\title{
ARMAZENAMENTO REFRIGERADO DE CAQUIS 'FUYU', SOB ATMOSFERA MODIFICADA COM ADSORÇÃO DE ETILENO'
}

\author{
LEANDRO CAMARGO NEVES ${ }^{2}$, LUCIANO LUCCHETTA ${ }^{3}$, LEONOR MARINI ${ }^{4}$, MARCIO ZANUZZO 5 , \\ JOCEMAR ZANATTA ${ }^{6}$, CÉSAR VALMOR ROMBALDI ${ }^{7}$
}

\begin{abstract}
RESUMO - No presente trabalho, avaliou-se a influência da embalagem de PEBD e da adsorção de etileno, em caquis 'Fuyu', na manutenção da qualidade comercial e na vida útil pós-colheita dos frutos, em 2 safras experimentais (1999-2000 e 2000-2001). Os frutos foram colhidos no estádio de maturação amarelo-alaranjado, na empresa KIWIS'TRIN Ltda - Farroupilha-RS, limpos, selecionados, pré-resfriados e acondicionados em embalagens de PEBD, com ou sem a adsorção de etileno. Na safra de 1999-2000, os frutos foram armazenados a granel, em embalagens de PEBD de $22 \mu$ m, com capacidade para 12 e 40 frutos, e de $33 \mu \mathrm{m}$, com capacidade para 12 frutos, sendo que metade das embalagens possuía o sachê adsorvedor. No laboratório de Biotecnologia de Alimentos, da UFPel/DCTA, foram avaliadas as seguintes variáveis: Firmeza de polpa, sólidos solúveis totais (SST) e acidez total titulável (ATT). Verificou-se que os frutos embalados em PEBD de $22 \mu \mathrm{m}$, com capacidade para 12 frutos, com e sem o sachê de adsorção, apresentaram maior firmeza de polpa, menores teores de sólidos solúveis totais e maiores níveis de acidez total titulável, sugerindo atraso na maturação. Na safra de 2000-2001, foram testados o armazenamento a granel e o armazenamento em embalagens de PEBD de $22 \mu$ m, com capacidade para 12; 18 e 24 frutos, com e sem a utilização de sachê. Observou-se que os frutos acondicionados nas embalagens de $22 \mu \mathrm{m}$ de espessura para 12 frutos, com o sistema de adsorção de etileno, apresentaram maturação mais lenta, com excelente manutenção da qualidade organoléptica.
\end{abstract}

Palavras-Chave: Embalagem, análise sensorial, conservação, Diospyrus kaki L.

\section{COLD STORAGE OF 'FUYU' PERSIMMONS, UNDER MODIFIED ATMOSPHERE WITH ETHYLENE'S ADSORPTION}

\begin{abstract}
It was tested the utilization of low-density polyethylene (LDPE) packages and the use of ethylene adsorber, of persimmons cv. 'Fuyu', with the objective of improving commercial quality and the shelf-life of the fruits, in 2 experimental seasons (1999/2000 e 2000/2001). The fruits were harvested at the yellow-orange ripening stage in the company KIWIS'TRIN Ltda, in Farroupilha/RS, cleaned, selected, pre-refrigerated and packed in LDPE packages with and without ethylene adsorption. In the season 1999/2000 the fruits were stored without packaging, in LDPE packages of $22 \mu \mathrm{m}$ with capacity for 12 and 40 fruits, and of $33 \mu \mathrm{m}$ with capacity for 12 fruits, since half of the packages had the ethylene adsorber sachet. At the laboratory of Biotechnology of Food of UFPel/DCTA it was evaluated the following variables: pulp firmness, total soluble solid (TSS) and total titratable acidity (TTA). It was found that the fruits packed in LDPE of $22 \mu \mathrm{m}$ with capacity for 12 fruits with and without adsorption sachet demonstrated higher pulp firmness, lower contents of total soluble solids and higher levels of total titratable acidity, suggesting a ripening delay. In the season 2000/2001 it was tested the storage without packaging, in packages of $22 \mu \mathrm{m}$ with capacity for 12, 18 and 24 fruits, with and without the utilization of sachet. It was noticed that the fruits packed in packages having a thickness of $22 \mu \mathrm{m}$ for 12 fruits, with the system of ethylene adsorption, demonstrated slower ripening and excellent maintenance of organoleptic quality.
\end{abstract}

Index Terms: Packaking, sensorial analysis, conservation, Diospyrus kaki L.

\section{INTRODUÇÃO}

Dentre as principais cultivares de caquis (Diospyrus kaki, L.) plantadas comercialmente no Brasil, a 'Fuyu' destaca-se por apresentar frutos grandes (180 a 280g), não adstringentes, coloração variando de amarelo-alaranjada a alaranjado-avermelhada, desprovidos de sementes (Sargent et al., 1993) e que possuem grande aceitação no mercado internacional

Para caquis, a maioria dos trabalhos realizados em pós-colheita, com o emprego de embalagens de polietileno de baixa densidade (PEBD), têm proporcionado resultados promissores (Moura et al., 1997). Porém, a comparação desses resultados é relativamente difícil, pois há grande variabilidade entre as metodologias empregadas. Assim, por exemplo, existem variações devido a efeitos edafoclimáticos, ponto de colheita, espessura da embalagem, número de frutos por embalagem, perfuração das embalagens e tratamentos pós-colheita.

MacRae (1987), na Nova Zelândia, relatou que caquis 'Fuyu' podem ser armazenados sob refrigerado, a $0{ }^{\circ} \mathrm{Ce} 95 \%$ de U.R, por apenas 4 semanas. Neste caso, o fator limitante à qualidade dos frutos foi a incidência de dano pelo frio, expressa na forma de gelatinização da polpa e diminuição da suculência, sem ter havido perda de firmeza. Nas mesmas condições de AR, Ben-Arie \& Zutkhi (1992), em Israel, trabalhando com caquis 'Fuyu' e com embalagens de PEBD de 60 e $80 \mu \mathrm{m}$, contendo 6 frutos por embalagem, observaram a manutenção das características adequadas para comercialização por 4 meses e meio. Brackmann et al. (1997), trabalhando com a mesma cultivar, no entanto, usando perfurações de 1,3 mm de diâmetro em embalagens de PEBD de $40 \mu \mathrm{m}$, conseguiram período máximo de 2 meses de AR, com manutenção da firmeza de polpa e baixos percentuais de escurecimento epidérmico. Sendo que, aos 3 meses de AR, os frutos ainda mantinham firmeza de polpa acima de $20 \mathrm{~N}$, porém apresentavam altos índices de escurecimento epidérmico.

Um dos aspectos mais relevantes da fisiologia pós-colheita do caqui 'Fuyu' é a sua alta sensibilidade ao etileno (Ben-Arie, 1995; BenArie \& Zutkhi, 1992). Segundo Warrington \& Weston (1990), concentrações de $0,1 \mu \mathrm{L} . \mathrm{L}^{-1}$ no meio reduzem o potencial de armazenamento de frutos sensíveis ao etileno. Em caquis 'Fuyu', o principal efeito do etileno é o incremento na velocidade de perda da firmeza e o desenvolvimento de podridões, desvalorizando-os comercialmente.

Deste modo, propôs-se a avaliação da influência da embalagem de PEBD e da adsorção de etileno, em caquis 'Fuyu', na manutenção da qualidade comercial e na vida útil pós-colheita dos frutos, em 2 safras experimentais (1999-2000 e 2000-2001).

\section{MATERIAIS E MÉTODOS}

O experimento foi realizado em duas safras experimentais, 1999-

\footnotetext{
${ }^{1}$ (Trabalho 028/2004). Recebido:11/03/2004. Aceito para publicação: 11/11/2004.

${ }^{2}$ UFRGS - Doutorando em Fitotecnia, C.P. 776, CEP 91501-970, Porto Alegre/RS. rapelbtu@ hotmail.com

${ }^{3}$ UFPel - Mestrando em Ciências, C.P. 354, CEP 96010-900, Pelotas/RS. luccheta@ufpel.tche.br

${ }^{4}$ UFPel - Mestrando em Ciências, C.P. 354, CEP 96010-900, Pelotas/RS. marini@ufpel.tche.br

${ }^{5}$ UFPel - Mestrando em Ciências, C.P. 354, CEP 96010-900, Pelotas/RS. zanuzzo@ufpel.tche.br

${ }^{6}$ UFPel - Bolsista Capes do Departamento de Ciências e Tecnologia Agroindustrial, C.P. 354, CEP 96010-900, Pelotas/RS. zanatta@ufpel.tche.br

${ }^{7}$ UFPel - Prof. Dr. Departamento de Ciências e Tecnologia Agroindustrial, C.P. 354, CEP 96010-900, Pelotas/RS. cesarvrf@ufpel.tche.br
} 
2000 e 2000-2001, na empresa KIWIS’TRIN Ltda - Farroupilha-RS. Os frutos da cultivar 'Fuyu' colhidos no estádio de fisiologicamente maturos, com coloração amarelo-alaranjada e massa média de $280 \mathrm{~g}$, foram limpos e selecionados quanto à ausência de danos e/ou podridões. Após a colheita, os frutos foram armazenados em câmara frigorífica a $0{ }^{\circ} \mathrm{C} \pm 0,5^{\circ} \mathrm{C}$, com 95 $\pm 3 \%$ de umidade relativa (UR), durante 24 horas, visando ao préresfriamento. Em seguida, foram embalados, testando-se o efeito da embalagem de PEBD e da adsorção de etileno sobre a conservação póscolheita dos frutos. Para a adsorção de etileno, utilizou-se sachê, marca comercial Longfresh ${ }^{\circledR}$, massa unitária de $9 \mathrm{~g}$, contendo silicato de alumínio e permanganato de potássio.

Imediatamente após o acondicionamento nas embalagens, os frutos foram mantidos em câmara frigorífica, nas condições citadas anteriormente.

As avaliações foram realizadas 24 horas após a colheita, aos 90 dias de AR e +5 dias sob temperatura ambiente $\left(22 \pm 3{ }^{\circ} \mathrm{C}\right.$ e $75 \pm 5 \%$ de UR), que seguiram os 90 dias de refrigeração.

\section{Safra de 1999-2000}

Os frutos foram colhidos no dia 07 de maio de 2000, apresentando valores médios de SST de $14,7^{\circ}$ Brix, firmeza de polpa média de $82 \mathrm{~N}$ (3 repetições de 15 frutos, colhidos aleatoriamente). Os tratamentos testados foram: 1 - frutos a granel, em caixa de $20 \mathrm{~kg}$ (controle);2-PEBD de $22 \mu \mathrm{m}$, com 40 frutos/embalagem; 3 - PEBD de $22 \mu \mathrm{m}+$ adsorvedor de etileno, contendo 40 frutos; 4 - PEBD de $22 \mu \mathrm{m}$, contendo 12 frutos; 5 - PEBD de $22 \mu \mathrm{m}+$ adsorvedor de etileno, contendo 12 frutos; 6 - PEBD de $33 \mu \mathrm{m}$, contendo 12 frutos, e 7 -PEBD de $33 \mu \mathrm{m}+$ adsorvedor de etileno, contendo 12 frutos, sendo o manuseio realizado em câmara frigorífica a $0 \pm 5^{\circ} \mathrm{C}$. As variáveis analisadas foram:

a) Firmeza de polpa, determinada com penetrômetro manual, ponteira de $8 \mathrm{~mm}$ de diâmetro. Os resultados foram expressos em $\mathrm{N}$ (Newtons).

b) Sólidos solúveis totais (SST), determinados por refratometria. Os resultados foram expressos em ${ }^{\circ}$ Brix.

c) Acidez total titulável (ATT), determinada pela titulação de $10 \mathrm{~g}$ de polpa, homogeneizada e diluída para $100 \mathrm{~mL}$, em água destilada, com solução padronizada de hidróxido de sódio a 0,01 N. Os resultados foram expressos em Cmol.L ${ }^{-1}$.

\section{Safra de 2000-2001}

A colheita dos caquis da cv. Fuyu foi no dia 15 de maio de 2001, quando os frutos se apresentavam com valores médios de SST de 14,6 ${ }^{\circ}$ Brix, firmeza de polpa média de 82,13 N (3 repetições de 15 frutos, colhidos aleatoriamente). Os tratamentos estudados foram: 1 - frutos a granel, em caixa de $20 \mathrm{~kg}$; 2 -PEBD de $22 \mu \mathrm{m}$, contendo 12 frutos; 3 -PEBD de $22 \mu \mathrm{m}$ + adsorvedor de etileno, contendo 12 frutos; 4 -PEBD de $22 \mu \mathrm{m}$, contendo 18 frutos; 5 - PEBD de $22 \mu \mathrm{m}+$ adsorvedor de etileno, contendo 18 frutos; 6 -PEBD de $22 \mu \mathrm{m}$, contendo 24 frutos, e 7 - PEBD de $22 \mu \mathrm{m}+$ adsorvedor de etileno, contendo 24 frutos. As variáveis avaliadas neste experimento foram as mesmas da safra de 1999-2000, incluindo-se a análise sensorial dos frutos. A análise sensorial foi realizada através de escala não segmentada, do tipo 0 a 9 , contendo duas amostras por tratamento, onde dez julgadores treinados avaliaram: aparência externa $(0=$ ruim e $9=$ =ótima mancha); maciez $(0=$ mole e $9=$ duro); coloração da epiderme $(0=$ amarelado e $9=$ avermelhado), e sabor ( $0=$ não característico e $9=$ característico). Também se realizou um teste de preferência, com dez julgadores treinados, através de escala hedônica de 5 pontos, variando de gostei muitíssimo (nota 5) a desgostei muitíssimo (nota 1), segundo Moraes (1988).

O delineamento experimental empregado, em ambas as safras, foi o inteiramente casualizado, com esquema fatorial $2 \times 3 \times 3$ (adsorvedor de etileno, tipos de embalagens, tempos de armazenamento), para a safra de 1999-2000, e fatorial 2x2x3 para a safra de 2000-2001, com 7 tratamentos e 3 repetições (15 frutos por repetição), em ambas as safras. Os dados foram submetidos à análise de variância e à comparação de médias, pelo teste de Tukey $(\mathrm{P} \leq 0,05)$.

\section{RESULTADOSEDISCUSSÃO}

A firmeza de polpa, uma das principais variáveis descritoras da qualidade dos frutos (Mitcham et al., 1998), na safra de 1999-2000, foi

TABELA 1 - Firmeza de polpa; sólidos solúveis totais; acidez total titulável, em caquis 'Fuyu', nas safras de 1999-2000 e 2000-2001, armazenados sob refrigeração $\left(0 \pm 0,5^{\circ} \mathrm{C}\right.$ e $95 \pm-5 \%$ de UR), durante 90 dias, seguido de 5 dias em temperatura ambiente $\left(22 \pm 3{ }^{\circ} \mathrm{C}\right.$ e $75 \pm 5 \%$ de UR) Farroupilha-RS.

tratamentos

\begin{tabular}{|c|c|c|c|c|c|c|c|c|c|c|c|}
\hline \multirow[b]{2}{*}{ Variáveis } & \multirow{2}{*}{\multicolumn{2}{|c|}{ sairas tempo }} & \multicolumn{9}{|c|}{ atamentos } \\
\hline & & & T1 & T2 & T3 & T4 & T5 & T6 & $\mathbf{T 7}$ & D.M.S. & C.V.(\%) \\
\hline \multirow{7}{*}{$\begin{array}{c}\text { Firmeza de } \\
\text { polpa }(\mathbf{N})\end{array}$} & \multirow{3}{*}{$\begin{array}{c}1999 / 2000 \\
*\end{array}$} & 1 & 81,25 & 81,25 & 81,25 & 81,25 & 81,25 & 81,25 & 81,25 & 0,9474 & 1,88 \\
\hline & & 90 & 27,69 & $50,05 b$ & $49,31 b$ & $66,15 \mathrm{a}$ & $64,49 a$ & $65,57 \mathrm{a}$ & $65,25 a$ & 0,5006 & 1,46 \\
\hline & & $90+5$ & $0 \mathrm{~d}$ & $34,57 \mathrm{c}$ & $34,20 \mathrm{c}$ & $53,61 \mathrm{a}$ & $47,12 b$ & $35,52 \mathrm{c}$ & $36,30 c$ & 0,5005 & 2,34 \\
\hline & \multirow{4}{*}{$\begin{array}{c}2000 / 2001 \\
* *\end{array}$} & & T1 & T2 & T3 & T4 & T5 & T6 & T7 & & \\
\hline & & 1 & 82,16 & 82,16 & 82,16 & 82,16 & 82,16 & 82,16 & 82,16 & 2,6184 & 5,14 \\
\hline & & 90 & $19,65 \mathrm{c}$ & $44.94 \mathrm{ab}$ & $48,18 \mathrm{a}$ & $44,19 \mathrm{ab}$ & $42,76 \mathrm{ab}$ & $38,26 b$ & $38,58 b$ & 1,7362 & 7,09 \\
\hline & & $90+5$ & $0 \mathrm{c}$ & $0 \mathrm{c}$ & $30,07 a$ & $0 \mathrm{c}$ & $15,75 b$ & $0 \mathrm{c}$ & $0 \mathrm{c}$ & 1,2750 & 31,43 \\
\hline \multirow{8}{*}{$\begin{array}{c}\text { Sólidos solúveis } \\
\text { totais } \\
\left({ }^{\circ} \text { Brix }\right)\end{array}$} & \multirow{4}{*}{$1999 / 2000$} & & T1 & T2 & T3 & T4 & T5 & T6 & T7 & & \\
\hline & & 1 & 14,67 & 14,67 & 14,67 & 14,67 & 14,67 & 14,67 & 14,67 & 1,0278 & 2,51 \\
\hline & & 90 & $17,42 \mathrm{a}$ & $16,13 b$ & $16,15 b$ & $14,88 \mathrm{c}$ & $14,85 \mathrm{c}$ & $14,62 \mathrm{c}$ & $15,28 \mathrm{bc}$ & 0,9286 & 2,13 \\
\hline & & $90+5$ & $18,65 a$ & $18,22 \mathrm{ab}$ & $18,39 a$ & $15,66 \mathrm{~d}$ & $16,01 \mathrm{~d}$ & $17,44 \mathrm{c}$ & $17,78 \mathrm{bc}$ & 0,4555 & 1,10 \\
\hline & \multirow{4}{*}{$2000 / 2001$} & & T1 & T2 & T3 & T4 & T5 & T6 & T7 & & \\
\hline & & 1 & 14,63 & 14,63 & 14,63 & 14,63 & 14,63 & 14,63 & 14,63 & 1,1693 & 2,87 \\
\hline & & 90 & $16,50 \mathrm{a}$ & $16,32 \mathrm{a}$ & $14,97 \mathrm{c}$ & $16,63 a$ & $15,47 \mathrm{bc}$ & $16,32 \mathrm{a}$ & $16,19 \mathrm{ab}$ & 0,8100 & 1,81 \\
\hline & & $90+5$ & $18,13 \mathrm{a}$ & $18,07 \mathrm{a}$ & $16,17 \mathrm{~b}$ & $18,20 \mathrm{a}$ & $17,88 \mathrm{a}$ & $18,33 \mathrm{a}$ & $18,44 \mathrm{a}$ & 0,5659 & 1,13 \\
\hline \multirow{8}{*}{$\begin{array}{c}\text { Acidez total } \\
\text { titulável (Cmol. } \\
\left.\mathbf{L}^{-1}\right)\end{array}$} & \multirow{4}{*}{$1999 / 2000$} & & T1 & T2 & T3 & T4 & T5 & T6 & T7 & & \\
\hline & & 1 & 1,033 & 1,033 & 1,033 & 1,033 & 1,033 & 1,033 & 1,033 & 1,0345 & 3,59 \\
\hline & & 90 & $0,667 \mathrm{c}$ & $0,815 b$ & $0,825 b$ & $0,936 a$ & $0,942 \mathrm{a}$ & $0,922 \mathrm{a}$ & $0,936 a$ & 0,4709 & 1,96 \\
\hline & & $90+5$ & $0,655 \mathrm{c}$ & $0,690 \mathrm{c}$ & $0,678 \mathrm{c}$ & $0,875 a$ & $0,770 \mathrm{~b}$ & $0,680 \mathrm{c}$ & $0,699 \mathrm{c}$ & 0,2602 & 1,49 \\
\hline & \multirow{4}{*}{$2000 / 2001$} & & T1 & T2 & T3 & T4 & T5 & T6 & $\mathbf{T 7}$ & & \\
\hline & & 1 & 1,031 & 1,031 & 1,031 & 1,031 & 1,031 & 1,031 & 1,031 & 1,1693 & 4,06 \\
\hline & & 90 & $0,515 d$ & $0,577 \mathrm{c}$ & $0,750 \mathrm{a}$ & $0,567 \mathrm{c}$ & $0,670 \mathrm{~b}$ & $0,542 \mathrm{~cd}$ & $0,563 c$ & 0,4227 & 2,54 \\
\hline & & $90+5$ & $0,338 \mathrm{c}$ & $0,390 b$ & $0,692 \mathrm{a}$ & $0,395 b$ & $0,428 \mathrm{~b}$ & $0,329 c$ & $0,330 \mathrm{c}$ & 0,3914 & 3,39 \\
\hline
\end{tabular}

As médias seguidas das mesmas letras, nas linhas, não diferem entre si, ao nível de $5 \%$ de probabilidade, pelo teste de Tukey.

D.M.S. - diferença mínima significativa, ao nível de 0,05

C.V. - Coeficiente de variação

* - T1: granel; T2: $22 \mu \mathrm{m} / 40$ fr.; T3: $22 \mu \mathrm{m} / 40$ fr. + abs; T4: $22 \mu \mathrm{m} / 12$ fr.; T5: $22 \mu \mathrm{m} / 12$ fr. + abs; T6: $33 \mu \mathrm{m} / 12$ fr.; T7: $33 \mu \mathrm{m} / 12$ fr. + abs.

** _ T1: granel; T2: $22 \mu \mathrm{m} / 12$ fr.; T3: $22 \mu \mathrm{m} / 12$ fr. + abs; T4: $22 \mu \mathrm{m} / 18$ fr.; T5: $22 \mu \mathrm{m} / 18$ fr. + abs; T6: $22 \mu \mathrm{m} / 24$ fr.; T7: $22 \mu \mathrm{m} / 24$ fr. + abs. 
influenciada pelo tempo de armazenamento, pela espessura do filme de PEBD e pelo número de frutos por embalagem, independentemente do uso do adsorvedor (Tabela 1).

Segundo Ben-Arie (1995), Rombaldi (1999) e Mitcham et al. (1998), a firmeza de polpa mínima recomendada para o consumo in natura de caquis da cv. Fuyu é 20 N. Sendo assim, todos os tratamentos, com exceção do controle, permitiram a manutenção de valores de firmeza de polpa superiores ao mínimo, na retirada dos frutos da câmara frigorífica (Tabela 1). Os frutos embalados em sacos de PEBD de $22 \mu \mathrm{m}$, contendo 12 frutos, sem o adsorvedor de etileno, apresentaram, ao final do período de AR, os maiores valores de firmeza de polpa $(66,2 \mathrm{~N})$. No entanto, não foi detectada diferença estatística entre esses frutos e os frutos acondicionados nas embalagens de $22 \mu \mathrm{m}$ com o sachê e os frutos acondicionados em embalagens de $33 \mu \mathrm{m}$, com ou sem o sistema de adsorção de etileno. Os frutos acondicionados a granel, em caixas unitárias, com capacidade de $20 \mathrm{~kg}$, foram os que apresentaram a mais rápida perda de firmeza de polpa, atingindo, aos 90 dias de $\mathrm{AR}, 27,7 \mathrm{~N}$. Estes resultados comprovam a eficácia da atmosfera modificada (AM) em consorciação com a refrigeração, frente ao AR convencional. BenArie \& Zutkhi (1992) também verificaram que, através da utilização de embalagens de $\mathrm{PEBD}$, os níveis de $\mathrm{CO}_{2}$ aumentaram e os de $\mathrm{O}_{2}$ diminuíram, resultando em redução da velocidade dos processos relativos ao amadurecimento, inclusive no amaciamento da polpa dos frutos.

Quando os caquis foram avaliados 5 dias após a transferência da câmara frigorífica para a temperatura ambiente, os frutos embalados em sacos de PEBD de $22 \mu \mathrm{m}$, contendo 12 frutos, sem o adsorvedor de etileno, apresentavam $54 \mathrm{~N}$ de firmeza de polpa, valor este bem acima do indicado para consumo, demonstrando, assim, a boa potencialidade de conservação. Já os frutos acondicionados a granel, apresentaram firmeza de polpa 'zero', pelo método de análise utilizado, demonstrando a precariedade da simples refrigeração dos frutos frente ao incremento qualitativo sugerido pela AM, no que concerne à manutenção dos atributos sensoriais.

Alguns autores também verificaram o efeito positivo da AM na conservação de caquis, em especial, na contenção da velocidade das perdas de firmeza de polpa (Ben-Arie \& Zutkhi, 1992; Maness et al., 1992). Porém, em geral, os melhores resultados foram observados com filmes de $40 \mu \mathrm{m}$, com microperfuração de 1,3 mm de diâmetro (Brackmann et al., 1997), e de $60 \mu \mathrm{m}$, contendo 6 frutos por embalagem (Ben-Arie \& Zutkhi, 1992).

As variações da firmeza de polpa dos caquis da cv. Fuyu, da safra de 2000-2001, diferentemente dos resultados obtidos na safra de 1999-2000, foram influenciadas pela utilização do sistema de adsorção de etileno (Tabela 1). Também houve efeito do número de frutos por embalagem sobre a firmeza de polpa dos caquis.

O uso do adsorvedor de etileno, nos frutos das embalagens para 12 frutos, reteve a firmeza de polpa durante a safra de 2000-2001, apresentando, ao final do período de AR bem como ao final do período de simulação de comercialização, valores acima do padrão mínimo de consumo de $20 \mathrm{~N}$ (Mitcham et al., 1998 e Rombaldi, 1999). Nos demais tratamentos, ao final do experimento, os frutos não possuíam firmeza de polpa mensurável, pelo método de análise utilizado, ou, no caso dos frutos das embalagens para 18 frutos com o sistema de adsorção, apresentaram firmeza de polpa abaixo do mínimo indicado para consumo.

O número de frutos por embalagem constituiu-se num fator importante na manutenção dos valores de firmeza de polpa, principalmente após a retirada dos frutos da câmara frigorífica. Nas embalagens contendo 12 frutos e o adsorvedor de etileno, detectaram-se os maiores valores de firmeza de polpa, tanto ao final do período de AR $(48,18 \mathrm{~N})$ como após a simulação de comercialização (30,07 N). Já os frutos acondicionados nas embalagens com capacidade para 24 frutos e o adsorvedor de etileno, ao final de 90 dias de AR, apresentavam firmeza de polpa de $38,58 \mathrm{~N}$, reduzindo drasticamente, após o período de simulação de comercialização.

Confirmando os relatos de Ben-Arie \& Zutkhi (1992), as diferenças de firmeza de polpa observadas entre os tratamentos, provavelmente, foram devidas às diferenças na composição gasosa formada dentro das embalagens, resultantes da respiração dos frutos e da espessura do filme utilizado, de forma que a interação adequada entre estes 2 fatores possibilita a manutenção da qualidade pós-colheita.

Durante a condução do experimento, na safra de 1999-2000, os maiores incrementos de SST foram observados em frutos armazenados a granel (Tabela 1). Neste caso, registrou-se incremento no teor de SST, de $14,6^{\circ}$ Brix, no momento da colheita, para $17,4^{\circ}$ Brix aos 90 dias de AR e $18,7^{\circ}$ Brix após o período de simulação de comercialização. Nos frutos armazenados em embalagens de $22 \mu \mathrm{m}$, contendo 12 frutos, sem ou com adsorção de etileno, foram detectados os menores aumentos, apresentando, na saída da câmara, teores de SST de 14,9 e 14,8 ${ }^{\circ}$ Brix, respectivamente, e, após a simulação de comercialização, teores de SST de 15,6 e $16,0^{\circ}$ Brix, respectivamente. Este comportamento concorda com vários autores (Ferri, 2000; Ben-Arie et al., 1996; Ben-Arie \& Zutkhi, 1992), que citam que há uma correlação inversa entre a conservabilidade e o acúmulo de SST.

Para a maioria dos frutos colhidos em estádio pré-climatérico, observa-se incremento do conteúdo de SST, ocasionado pela conversão de moléculas insolúveis para formas solúveis e/ou pela síntese 'de novo' (Kader, 1992). Em caquis 'Fuyu', os resultados têm sido contraditórios, e Ben-Arie et al. (1996) e Sargent et al. (1993) citam que há redução do teor de SST após a colheita. Entretanto, outros autores verificaram aumentos no teor de SST desde 5 aos 10 dias após a colheita, seguidos de redução (Maness et al., 1992). Moura et al. (1997) verificaram comportamento inverso, ou seja, um aumento do conteúdo de SST durante o AR, concordando com os resultados encontrados neste experimento.

Já na safra de 2000-2001, nas embalagens contendo 12 frutos e o adsorvedor de etileno, ocorreram os menores incrementos nos teores de SST, aumentando de $14,6^{\circ}$ Brix na colheita, para $15,0^{\circ}$ Brix, na saída da câmara, e $16,2^{\circ}$ Brix, após o período de simulação de comercialização.

Segundo Lyon et al. (1992), processos metabólicos relacionados com o avanço do amadurecimento, como a perda de firmeza de polpa, influem diretamente nos teores de SST. Assim, frutos em avançado estádio de amadurecimento, com baixa firmeza de polpa, apresentam teores mais elevados de SST, provavelmente pela dissociação de algumas moléculas e enzimas estruturais em compostos solúveis. Assim, pode-se estabelecer uma relação direta entre os menores incrementos de SST encontrados nos frutos acondicionados em embalagens contendo 12 frutos e adsorvedor de etileno, com os maiores valores de firmeza de polpa, evidenciando-se, então, um estádio menos avançado de amadurecimento.

De maneira geral, todos os tratamentos apresentaram reduções nos níveis de ATT, e a velocidade com que ocorrem, está diretamente relacionada à velocidade do metabolismo. Nos frutos armazenados em embalagens de $22 \mu \mathrm{m}$, contendo 12 frutos sem a utilização do adsorvedor de etileno, durante a safra de 1999-2000, observaram-se as menores reduções (Tabela 1). Ben-Arie \& Zutkhi (1992) descrevem que, em caquis 'Fuyu', embalados em sacos de PEBD, é possível constatar que o atraso na diminuição da ATT está diretamente relacionado à melhor conservação, enquanto nos frutos armazenados a granel foram detectadas as maiores reduções na ATT, caracterizando a maior atividade metabólica (Tabela 1).

Segundo Da-Silva et al. (1997), a diminuição da firmeza de polpa deve-se principalmente ao catabolismo de ácidos orgânicos, pelo metabolismo respiratório. Isto proporcionaria, portanto, uma tendência ao decréscimo da ATT. Porém Helbig et al. (1998) verificaram que, em ameixas, as variações de ATT seguem um comportamento quadrático, ou seja, um decréscimo inicial, seguido de um incremento na fase final. Deste modo, este comportamento pode ser explicado pela diminuição do conteúdo de ácidos orgânicos na primeira fase e geração de radicais ácidos, provenientes da hidrólise de componentes da parede celular, na segunda fase.

Na safra de 2000-2001, observou-se o mesmo comportamento da safra de 1999-2000, ou seja, redução na ATT, em todos os tratamentos 
testados durante o período experimental (Tabela 1). As maiores reduções, caracterizando maior atividade metabólica, ocorreram em frutos acondicionados nas embalagens com capacidade para 24 frutos, com e sem a utilização do adsorvedor de etileno e nos frutos armazenados a granel. As menores reduções ocorreram em frutos acondicionados nas embalagens com capacidade para 12 frutos, com a utilização do adsorvedor de etileno. A resposta é esperada para a maioria dos frutos, excetuando-se os frutos de caroço, como pêssegos, ameixas e nectarinas que, em estádios mais avançados de maturação, aumentam a ATT (Helbig et al., 1998).

Com relação às diferenças encontradas quanto ao efeito benéfico do adsorvedor nas safras de 1999-2000 e 2000-2001, pressupõese que as condições de temperatura e UR, às quais os frutos foram submetidos em pré-colheita, possam ter influência direta nos resultados obtidos. No ano de 2000 ( $1^{\text {a }}$ safra experimental), verificou-se intensa pluviosidade e baixa luminosidade durante os meses de março a maio, fase em que os frutos estão no desenvolvimento final dos atributos sensoriais. Já no ano de 2001 ( $2^{\mathrm{a}}$ safra experimental), as condições foram de pluviosidade e luminosidade normais para a época, podendo ser este fator preponderante para a eficácia do sachê adsorvedor nesta safra.

Na saída da câmara, os frutos das embalagens com capacidade para 12 e 18 frutos, sem e com o adsorvedor de etileno, apresentaram a melhor aparência externa (Figura 1). Os frutos das embalagens com 24 frutos, sem e com o sistema de adsorção de etileno, bem como os frutoscontrole, já não apresentavam um padrão de qualidade satisfatório, sugerindo um avançado estádio de amadurecimento. Após o período de simulação de comercialização, as diferenças entre os tratamentos intensificaram-se. Somente os frutos das embalagens para 12 e 18 frutos, com o sistema de adsorção de etileno, mantiveram a aparência externa adequada à comercialização. Nos demais tratamentos, devido à presença de deteriorações, por ferimento ou até mesmo por perda excessiva de umidade, houve um comprometimento na qualidade visual. Essa resposta pode ser explicada pelo fato de que a interação entre a espessura do filme de PEBD e o número de frutos por embalagem (Mosca et al., 1999; Ben-Arie \& Zutkhi, 1992), bem como o uso do adsorvedor (Ferri, 2000) possibilitaram um atraso na velocidade do metabolismo de amadurecimento.

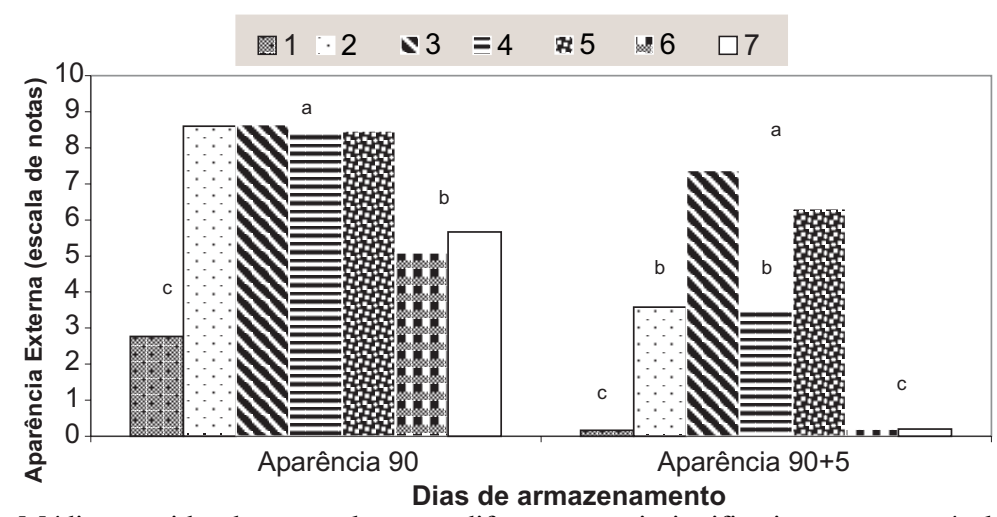

Médias seguidas da mesma letra não diferem entre si, significativamente, ao nível de $5 \%$ de probabilidade, pelo teste de Tukey.

T1: granel; T2: $22 \mu \mathrm{m} / 12$ fr.; T3: $22 \mu \mathrm{m} / 12$ fr. + abs; T4: $22 \mu \mathrm{m} / 18$ fr.; T5: $22 \mu \mathrm{m} /$ 18 fr. + abs; T6: $22 \mu \mathrm{m} / 24$ fr.; T7: $22 \mu \mathrm{m} / 24$ fr. + abs.

FIGURA 1 - Aparência externa de caquis da cv. Fuyu, através de análise sensorial - escala não segmentada $(0=$ ruim a $9=$ excelente), safra de 2000-2001, armazenados sob refrigeração $(0 \pm 0,5$ ${ }^{\circ} \mathrm{Ce} 95 \pm-5 \%$ de UR), durante 90 dias, seguido de 5 dias em temperatura ambiente $\left(22 \pm 3{ }^{\circ} \mathrm{C}\right.$ e $75 \pm 5 \%$ de UR) Farroupilha-RS.

Na safra de 2000-2001, aos 90 dias de AR, somente os frutoscontrole, pelo avançado estádio de amadurecimento, apresentavam coloração vermelha adequada para a comercialização (Figura 2). Os demais tratamentos ainda apresentavam, na epiderme, pontuações amareladas. Ao final do período de simulação de comercialização, todos os frutos das embalagens com capacidade para 12 e 18 frutos, sem e com a utilização do adsorvedor de etileno, evoluíram a coloração da epiderme, apresentando-se avermelhada brilhante. Segundo alguns autores, esta é uma importante característica sensorial do caqui 'Fuyu' maturo, que influencia, na maioria das vezes, a decisão do consumidor (Ferri, 2000; Rombaldi, 1999). Os frutos-controle, apesar da manutenção da coloração avermelhada da epiderme, nas demais características sensoriais, indicavam um padrão de qualidade impróprio para a comercialização.

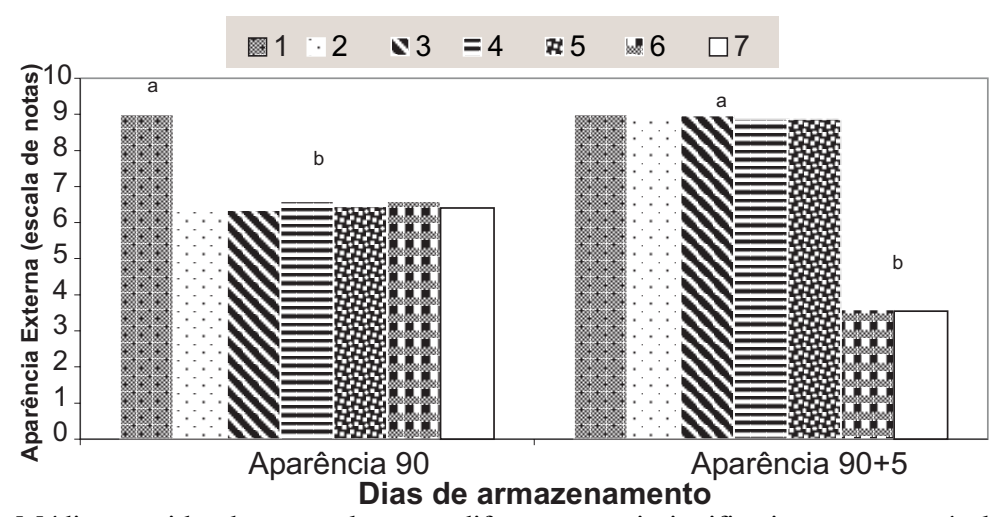

Médias seguidas da mesma letra não diferem entre si, significativamente, ao nível de $5 \%$ de probabilidade, pelo teste de Tukey.

T1: granel; T2: $22 \mu \mathrm{m} / 12$ fr.; T3: $22 \mu \mathrm{m} / 12$ fr. + abs; T4: $22 \mu \mathrm{m} / 18$ fr.; T5: $22 \mu \mathrm{m} /$ 18 fr. + abs; T6: $22 \mu \mathrm{m} / 24$ fr.; T7: $22 \mu \mathrm{m} / 24$ fr. + abs.

FIGURA 2 - Coloração de caquis da cv. Fuyu, através de análise sensorial - escala não segmentada $(0=$ amarelado a $9=$ vermelho brilhante), safra de 2000-2001, armazenados sob refrigeração $\left(0 \pm 0,5^{\circ} \mathrm{Ce} 95 \pm-5 \%\right.$ de UR), durante 90 dias, seguido de 5 dias em temperatura ambiente $\left(22 \pm 3{ }^{\circ} \mathrm{Ce} 75\right.$ $\pm 5 \%$ de UR) Farroupilha-RS.

Os frutos das embalagens com capacidade para 12 e 18 frutos, sem e com o sistema de adsorção de etileno, apresentaram, aos 90 dias de AR, elevada consistência (Figura 3), sendo esta uma importante característica desta cultivar no momento do consumo, representando maior resistência ao manuseio/transporte (Ben-Arie, 1995; Sargent et al., 1993). Já os frutos das embalagens para 24 frutos, sem e com o adsorvedor de etileno, apresentavam consistência intermediária, praticamente no limite do padrão mínimo de consumo, condicionado-se a estes frutos quase o consumo imediato. Após o período de comercialização simulada, somente os frutos com o adsorvedor de etileno das embalagens de $12 \mathrm{e}$ 18 frutos apresentavam consistência na polpa detectável pelos julgadores, sendo que os frutos acondicionados em embalagens com capacidade para 12 frutos foram os que apresentaram a melhor manutenção deste atributo sensorial, comprovando os resultados obtidos pela determinação, usando-se penetrômetro, na safra de 20002001 (Tabela 1).

Os frutos acondicionados nas embalagens com capacidade para 12 e 18 frutos, sem e com o adsorvedor de etileno, assim como os frutoscontrole apresentavam sabor característico, aos 90 dias de AR (Figura 4). Já os caquis das embalagens para 24 frutos, sem e com o sistema de adsorção de etileno, apresentaram sabor amargo. Provavelmente, a elevada concentração de $\mathrm{CO}_{2}$ tenha proporcionado fermentação destes frutos e conseqüente alteração no sabor. Após o período de simulação de comercialização, a utilização do adsorvedor de etileno, nas embalagens de capacidade para 12 frutos, proporcionou a melhor manutenção do sabor. Já nas embalagens com capacidade para 24 frutos, sem e com o adsorvedor, a exemplo da saída da câmara aos 90 dias de AR, os frutos apresentaram uma intensificação do sabor amargo. 


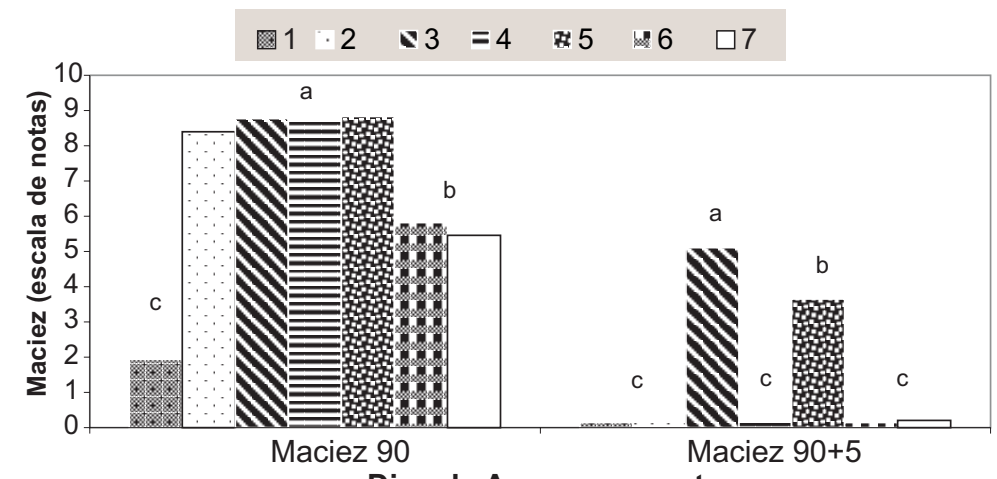

Dias de Armazenamento

Médias seguidas da mesma letra não diferem entre si, significativamente, ao nível de $5 \%$ de probabilidade, pelo teste de Tukey.

T1: granel; T2: $22 \mu \mathrm{m} / 12$ fr.; T3: $22 \mu \mathrm{m} / 12$ fr. + abs; T4: $22 \mu \mathrm{m} / 18$ fr.; T5: $22 \mu \mathrm{m} /$ 18 fr. + abs; T6: $22 \mu \mathrm{m} / 24$ fr.; T7: $22 \mu \mathrm{m} / 24$ fr. + abs.

FIGURA 3 - Maciez de caquis da cv. Fuyu, através de análise sensorial escala não segmentada $(0=$ macio a $9=$ duro $)$, safra de 2000 2001 , armazenados sob refrigeração $\left(0 \pm 0,5^{\circ} \mathrm{Ce} 95 \pm-5 \%\right.$ de UR), durante 90 dias, seguido de 5 dias em temperatura ambiente $\left(22 \pm 3{ }^{\circ} \mathrm{C}\right.$ e $75 \pm 5 \%$ de UR) Farroupilha-RS.

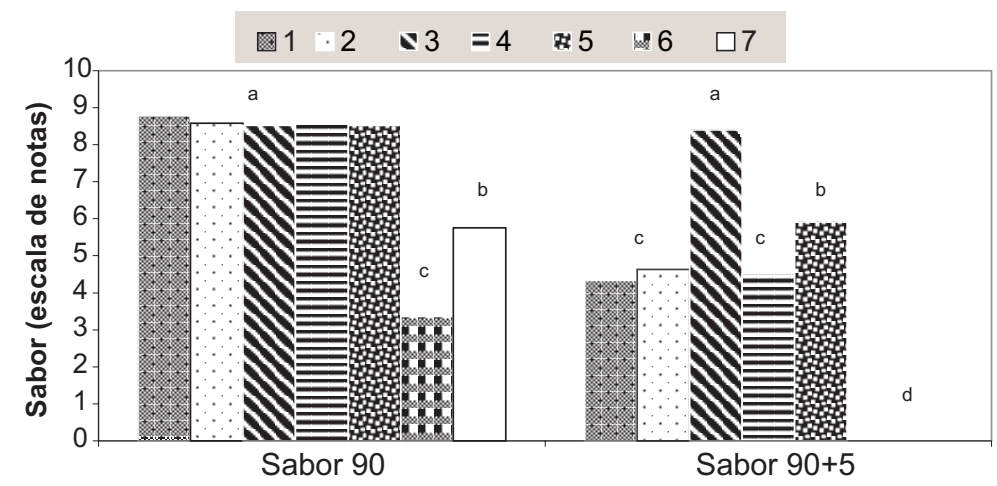

Dias de Armazenamento

Médias seguidas da mesma letra não diferem entre si, significativamente, ao nível de $5 \%$ de probabilidade, pelo teste de Tukey.

T1: granel; T2: $22 \mu \mathrm{m} / 12$ fr.; T3: $22 \mu \mathrm{m} / 12$ fr. + abs; T4: $22 \mu \mathrm{m} / 18$ fr.; T5: $22 \mu \mathrm{m} /$ 18 fr. + abs; T6: $22 \mu \mathrm{m} / 24$ fr.; T7: $22 \mu \mathrm{m} / 24$ fr. + abs.

FIGURA 4 - Sabor de caquis da cv. Fuyu, através de análise sensorial escala não segmentada $(0=$ não característico a 9=característico), safra de 2000-2001, armazenados sob refrigeração $\left(0 \pm 0,5^{\circ} \mathrm{Ce} 95 \pm-5 \%\right.$ de UR), durante 90 dias, seguido de 5 dias em temperatura ambiente $\left(22 \pm 3{ }^{\circ} \mathrm{C}\right.$ e 75 $\pm 5 \%$ de UR) Farroupilha-RS.

\section{CONCLUSÕES}

1. A embalagem de PEBD de $22 \mu \mathrm{m}$ de espessura, com capacidade para 12 frutos, para caquis 'Fuyu', possibilita um período seguro de AR de 90 dias, diminuindo a velocidade dos processos relacionados ao amadurecimento.

2. Os testes sensoriais comprovaram os resultados obtidos nas análises laboratoriais, confluindo para a embalagem de $22 \mu \mathrm{m}$ de espessura, com capacidade para 12 frutos, os melhores resultados.

\section{REFERÊNCIAS}

BEN-ARIE; ZUTKHI, Y. Extending the storage life of "Fuyu" persimmon by modified-atmosphere packaging. HortScience, Alexandria v.27, n.7, p.811-813, 1992.

BEN-ARIE, R. Commercial quality of "Fuyu" persimmon. Posthavest Biology and Technology, v.14, n.3, p.311-317, 1995.

BEN-ARIE, R.; SAKS, Y.; SONEGO, L.; FRANK, A. CelI wall metabolism in gibberellin-treated persimmon fruits. Plant Growth Regulation, Amsterdam, n.19, p.25-33, 1996.

BRACKMANN, A., MAZARO, S.M; SAQUET, A.A. Frigoconservação de caquis (Diospyrus kaki, L.) das cultivares Fuyu e Rama Forte. Revista Ciência Rural, Santa Maria, v.27, n.4, p.561 -565, 1997.

DA-SILVA, R.; FRANCO, C.M.L.; GOMES, E. Pectinases, hemicelulases e celulases, ação, produção e aplicação no processamento de alimentos: revisão. Revista Brasileira de Ciência e Tecnologia de Alimentos, v.31, n.2, p.249-260, 1997.

FERRI, V.C. Controle da maturação e conservação de caquis (Diospyrus kaki, L.) cultivar Fuyu. Pelotas. 2000. 103f. Tese (Doutorado em agronomia) - Faculdade de Agronomia Eliseu Maciel, Universidade Federal de Pelotas, Pelotas, 2000.

HELBIG, V.E.; ROMBALDI, C. V.; CASTRO, L.A. S. de. Ponto de colheita e tempo de armazenamento refrigerado na conservação de ameixas (Prunus salicina, lindl) cvs. Pluma 7 e Wade ${ }^{1}$. In: CONGRESSO BRASILEIRODE CIÊNCIAE TECNOLOGIADEALIMENTOS, 16. 1998, Rio de Janeiro. Anais... Rio de Janeiro: SBCTA, 1998. CD-ROM trabalho 110.

KADER, A.A. Postharvest technology of horticultural crops ( $\left.2^{\text {nd }} e d.\right)$, University of California, 1992.

LYON, B.G.; SENTER, S.D.; PAYNE, J.A. Quality characteristics of oriental persimmons (Diospyrus kaki, L.) cv. Fuyu grow in the southeastern United States. Journal of Food Science, Athens. v.57, n.3, p.693695, 1992

MAcRAE, E.A. Development at chilling injury in New Zealand grown fuyu' persimmon during storage. New Zealand Journal of Experimental Agriculture, Auckland, n.15, p.333-344, 1987.

MANESS, N.O.; BRUSEWITZ, G.H.; MCCOLLUM, T.G. Internal variation in peach fruit firmness. HortScience, Alexandria, v.27, n.8, p.903905, 1992.

MITCHAM, J.E.; CRISOSTO, C.H.; KADER, A.A. Recommendations for maintaining postharvest quality. Department of Pomology, University al California, Davis, 120 p, 1998.

MORAES, M.A.C. Métodos para avaliação sensorial dos alimentos. 6 . ed. Campinas: Editora Unicamp. 1988.

MOSCA, J. L.; MUGNOL, M. M.; VIEITES, R. L. Atmosfera modificada na pós-colheita de frutas e hortaliças. Botucatu: FEPAF, 1999. 28p.

MOURA, M.A.; LOPES, L.C.; CARDOSO, A.A.; MIRANDA, L.C.G. Efeito da embalagem e do armazenamento no amadurecimento do caqui. Pesquisa Agropecuária Brasileira, Brasília, v.32, n. 6, p.11051109, 1997.

ROMBALDI, C. V. Armazenamento de caqui. Jornal da Fruta, n.232, p.4. 1999.

SARGENT, SA.; CROCKER, T.E.; ZOELLNER J.J. Storage characteristics of 'Fuyu' persimmons. Proceedings FIa. State Horticulturae Society, Gainesville, n.106, p.131-134, 1993.

WARRINGTON, I.J.; WESTON, G.C. Kiwifruit science and management. Auckland, Ray Richards Publisher, 1990. 576p. 